\title{
Hubungan Teknik Jahitan terhadap Gejala Infeksi Luka Perineum pada Ibu Nifas Hari Keenam di BPM Sri Utami Surabaya
}

\author{
Setiana Andarwulan \\ D III Kebidanan, Fakultas IImu Kesehatan, Universitas PGRI Adi Buana Surabaya \\ *corresponding author \\ Setiana Andarwulan \\ setianaandarwulan@unipasby.ac.id
}

\begin{abstract}
Abstrak
Luka perineum hampir terjadi pada setiap persalinan pertama dan tidak jarang berkelanjutan. Luka perineum terjadi karena adanya ekstensi kepala berlebihan, mayoritas pada saat terjadi putaran paksi. Asuhan persalinan normal menyarankan untuk memakai teknik jahitan yang paling efisien terhadap luka dalam melakukan penjahitan. Jahitan jelujur memiliki kelebihan dapat menutup luka lebih rapat. Jahitan ini digunakan untuk menutup mukosa dan otot perineum, penjahitan secara terputus dapat dilakukan jika luka mencapai lapisan otot perineum. Sehingga luka perineum dapat menutup dan tidak terjadi infeksi. Populasi yang digunakan sebanyak 22 orang. Teknik sampling yang digunakan adalah total sampling. Dalam penelitian ini menggunakan teknik experimental yang kemudian dilakukan randomisasi antara teknik jahitan jelujur dan terputus. Uji yang dilakukan untuk penelitian ini adalah uji Chisquare. Hasilnya nilai dari Asym. Sig sebesar 0,269 >0,05, sehingga dapat diambil kesimpulan bahwa adanya hubungan yang signifikan antara teknik jahitan dan terjadinya infeksi di BPM Sri Utami Surabaya.
\end{abstract}

Kata kunci: Perineum; Infeksi; Jahitan; NIfas

\section{The Relationship of Sewing Techniques with Symptoms of Perineal Wound Infection on The Sixth Day of Postpartum Mothers at BPM Sri Utami Surabaya}

\begin{abstract}
Perineal injury occurs almost every first labor and is not uncommon. Perineal injuries occur due to excessive head extension, the majority of which occur during rotation. Normal childbirth care recommends using the most efficient suture technique for the wound in suturing. Bold stitches have the advantage of being able to close the wound more tightly. This suture is used to close the mucosa and perineal muscle, suturing can be interrupted if the wound reaches the perineal muscle layer. So that the perineal wound can close and no infection occurs. The population used was 22 people. The sampling technique used is total sampling. In this study using experimental techniques which is then randomized between bare and interrupted suture techniques. The test conducted for this study is the Chisquare test. The result is the value of Asym. Sig of 0.269>0.05, so it can be concluded that there is
\end{abstract}


Hubungan Teknik Jahitan terhadap Gejala Infeksi Luka Perineum pada Ibu Nifas Hari Keenam di BPM Sri Utami Surabaya

a significant relationship between the stitching technique and the occurrence of infection in BPM Sri Utami Surabaya.

Keyword: Perineal; Infection; Sutures; Postpartum

\section{Pendahuluan}

Masa nifas (puerperium) terjadi pada periode pascanatal yang merupakan keadaan yang kritis dalam kehidupan ibu dan bayinya. Perubahan yang besar terjadi selama periode ini yang menetukan kesejahteraan ibu dan bayinya. Namun terkadang waktu ini diabaikan dalam pemberian layanan yang berkualitas. Sehingga kurang tepatnya pelayanan menyebabkan kesehatan yang buruk bahkan kematian. Sebagian besara kematian ibu dan bayi terjadi selama masa ini. Hal ini dapat dikarenakan tingkat penyediaan perawatan terampil lebih rendah daripada tingkat sebelumnya (WHO, 2013).

Asuhan persalinan normal memberikan rekomendasi untuk menggunakan jahitan yang lebih efektif dan efisien dalam mendekatkan jaringan. Jahitan jelujur digunakan untuk lapisan vagina dan otot perineum, Jahitan terputus dapat dilakukan bila luka mencapai lapisan otot perineum. Penggunaan benang kromik 2.0 atau 3.0 yang sifatnya lentur, kuat dan tahan lama. Pengelolaan trauma pada luka perineum ditekankan pada luka derajat satu dan dua yang dilakukan oleh bidan sebagai penolong (APN, 2017).

Berdasarkan World Health Organization (WHO) pada tiap harinya sekitar 810 wanita meninggal karena kehamilan dan persalinan. Antara tahun 2000-2017 rasio kematian ibu dari 100.000 kelahiran hidup sekitar $38 \%$ di seluruh dunia. $94 \%$ dari semua kematian itu berasal dari pendapatan yang rendah (WHO, 2017). Di negara ASEAN kematian ibu tertinggi dipegang oleh Laos sebanyak 350/100.000 kelahiran hidup dan selanjutnya disusul oleh Indonesia dengan 305/100.000 kelahiran hidup (Endang L, 2017).

Perineum terletak diantara vagina dan lubang anus. Pada beberapa wanita yang memiliki kesempatan untuk melahirkan secara normal, mereka trauma dengan pengalaman mereka tentang manajemen nyeri pada perineum yang buruk, sehingga memutuskan untuk 
Hubungan Teknik Jahitan terhadap Gejala Infeksi Luka Perineum pada Ibu Nifas Hari Keenam di BPM Sri Utami Surabaya

melakukan operasi caesar saja. Pada sebagian wanita yang hamil pertama kali akan semakin khawatir tentang konsekuensi dari luka perineum yang berhubungan dengan morbiditas (Dudley, Kettle \& Ismail, 2013).

Dengan demikian adanya luka jahit pada ibu nifas akibat tindakan episiotomi maupun secara spontan, sangatlah membutuhkan perawatan secara benar dari ibunya sendiri dalam percepatan penyembuhan luka. Perawatan perineum tentang cara mencuci daerah genitalia dengan lembut memakai sabun dan air DTT kemudian dikeringkan (APN, 2017).

Studi pendahuluan yang dilakukan oleh peneliti di BPM Sri Utami Surabaya mendapatkan di mana jumlah ibu postpartum pada bulan Mei 2019 sebanyak 10 orang. Dari hasil observasi melalui lembar observasi secara langsung pada saat pengambilan data awal menyatakan ditemukan 2 orang ibu mengalami infeksi dikarenakan jahitan tidak menyatu. Berdasarkan latar belakang uraian tersebut, peneliti merasa perlu melakukan penelitian tentang Hubungan Teknik Jahitan Terhadap Gejala Infeksi Luka Perineum Pada Ibu Nifas Hari Keenam Di BPM Sri Utami Surabaya. Tujuan penelitian adalah: 1) mengidentifikasi teknik jahitan pada ibu nifas di BPM Sri Utami Surabaya, 2) mengidentifikasi gejala infeksi luka perineum pada ibu nifas hari keenam di BPM Sri Utami Surabaya, 3) menganalisis hubungan teknik jahitan terhadap gejala infeksi luka perineum pada ibu nifas hari keenam di BPM Sri Utami Surabaya.

Penelitian yang sebelumnya dilakukan oleh Herawati (2010) menunjukan bahwa terdapat hubungan antara perawatan perineum dengan penyembuhan luka. Selain itu penelitian yang dilakukan oleh Aslam et al. (2015), yang menyatakan bahwa ada hubungan antara teknik jahitan dengan luka perineum. Sriani et al. (2015) dalam penelitiannya juga menyatakan ada hubungan antara kejadian luka infeksi dengan perawatan vulva hygine yang baik.

\section{Metode}

Desain penelitian yang dipakai dalam penelitian berupa analitik deskritif. Dengan pendekatan cross sectional. Penelitian dilaksanakan pada bulan Juni - Agustus 2019 di BPM Sri Utami Surabaya dengan menggunakan 22 responden ibu nifas. Dengan teknik sampling yang digunakan adalah total sampling, 
Hubungan Teknik Jahitan terhadap Gejala Infeksi Luka Perineum pada Ibu Nifas Hari Keenam di BPM Sri Utami Surabaya

karena jumlah populasi kurang dari 100 (Nursalam, 2013).

Dari seluruh responden diberikan perlakuan dengan 11 responden dilakukan jahitan jelujur dan 11 responden dilakukan jahitan terputus. Sedangkan dalam menentukan gejala infeksi luka perineum dilakukan observasi secara langsung dengan melalui lembar observasi dari peneliti sebelumnya (Sriani et al., 2015). Penentuan skor keseluruhan diperoleh berdasarkan nilai median: Skor tertinggi $x$ jumlah pernyataan $=1 \times 5=5$ Skor terendah $\mathrm{x}$ jumlah pernyataan $=0 \times 5=0$ Nilai $=$ $5+0=5 / 2=2.5=3$. Jika jumlah skor $<3$ maka gejala infeksi luka perineum baik, sedangkan jika jumlah skor $\geq 3$ maka gejala infeksi luka perineum memburuk.

\section{Metode analisis yang} digunakan adalah Chisquare dengan nilai signifikasi $\alpha=0,05$.

\section{Hasil}

Tabel 1. Deskripsi Umur Responden Ibu Nifas Di \begin{tabular}{ccc}
\multicolumn{3}{c}{ BPM Sri Utami } \\
$\begin{array}{c}\text { Umur } \\
\text { Responden }\end{array}$ & $\begin{array}{c}\text { Jumlah } \\
\text { Responden }\end{array}$ & $\begin{array}{c}\text { Prosentase } \\
(\%)\end{array}$ \\
\hline $20-35$ tahun & 18 & 81,8 \\
$>35$ tahun & 4 & 18,2 \\
\hline Total & 22 & 100,0
\end{tabular}

Sumber: hasil analisis data September 2019

Berdasarkan tabel.1 diatas menunjukkan bahwa setengahnya dari 22 responden berumur $20-35$ tahun sebanyak 18 orang $(81,8 \%)$ sedangkan yang berumur $>35$ tahun hanya 4 orang $(18,2 \%)$.

Tabel 2. Deskripsi Pendidikan Responden Ibu Nifas Di BPM Sri Utami

\begin{tabular}{ccc}
\hline $\begin{array}{c}\text { Pendidikan } \\
\text { Responden }\end{array}$ & $\begin{array}{c}\text { Jumlah } \\
\text { Responden }\end{array}$ & $\begin{array}{c}\text { Prosentase } \\
(\%)\end{array}$ \\
\hline SMP & 4 & 18,2 \\
SMA & 17 & 77,3 \\
PT & 1 & 4,5 \\
\hline Total & 22 & 100,0 \\
\hline Sumber: hasil analisis data September 2019
\end{tabular}

Berdasarkan tabel 2 diatas menunjukkan bahwa setengahnya dari 22 responden yang berada di jenjang pendidikan SMA berjumlah 17 orang $(77,3 \%)$, sedangkan responden yang berada di jenjang pendidikan SMP berjumlah 4 orang ( $18,2 \%$ ) dan responden yang berada pada di jenjang Perguruan Tinggi sebanyak 1 orang $(4,5 \%)$.

Tabel 3. Deskripsi Pendidikan Responden lbu Nifas Di BPM Sri Utami

\begin{tabular}{ccc}
\hline $\begin{array}{c}\text { Pekerjaan } \\
\text { Responden }\end{array}$ & $\begin{array}{c}\text { Jumlah } \\
\text { Responden }\end{array}$ & $\begin{array}{c}\text { Prosentase } \\
(\%)\end{array}$ \\
\hline IRT & 17 & 77,3 \\
SWASTA & 4 & 18,2 \\
WIRASWASTA & 1 & 4,5 \\
\hline Total & 22 & 100,0 \\
\hline Sumber: hasil analisis data September 2019
\end{tabular}

Berdasarkan tabel 3 lebih dari setengahnya responden sebanyak 17 orang $(77,3 \%)$ responden bekerja sebagai IRT, sedangkan sebanyak 4 orang $(18,2 \%)$ dan sebanyak 1 orang $(4,5 \%)$ bekerja sebagai Wiraswasta. 
Hubungan Teknik Jahitan terhadap Gejala Infeksi Luka Perineum pada Ibu Nifas Hari Keenam di BPM Sri Utami Surabaya

Tabel 4. Deskripsi Teknik Jahitan Responden Ibu

\begin{tabular}{ccc}
\multicolumn{3}{c}{ Nifas Di BPM Sri Utami } \\
\hline Teknik & $\begin{array}{c}\text { Jumlah } \\
\text { Jesponden }\end{array}$ & $\begin{array}{c}\text { Prosentase } \\
(\%)\end{array}$ \\
\hline Jelujur & 11 & 50,0 \\
Terputus & 11 & 50,0 \\
\hline Total & 22 & 100,0 \\
\hline Sumber: hasil analisis data September 2019
\end{tabular}

Berdasarkan data penelitian diatas tabel 4 menunjukkan bahwa jumlah responden yang dilakukan jahitan jelujur sebanyak 11 orang (50\%), sedangkan jahitan terputus sebanyak 11 orang (50\%).

Tabel 5. Deskripsi Kejadian Infeksi Responden lbu Nifas Di BPM Sri Utami

\begin{tabular}{ccc}
\hline Kejadian & $\begin{array}{c}\text { Jumlah } \\
\text { Responden }\end{array}$ & $\begin{array}{c}\text { Prosentase } \\
(\%)\end{array}$ \\
\hline Infeksi & 4 & 18,18 \\
Tidak Infeksi & 18 & 81,82 \\
\hline Total & 22 & 100,0 \\
\hline Sumber: hasil analisis data September 2019
\end{tabular}

Berdasarkan data penelitian diatas tabel 5 menunjukkan bahwa jumlah responden yang mengalami infeksi sebanyak 4 orang $(18,18 \%)$, sedangkan yang tidak infeksi sebanyak 18 orang $(81,82 \%)$.

Tabel 6. Analisis Chi-square tests Teknik Jahitan Responden Ibu Nifas Di BPM Sri Utami

\begin{tabular}{|c|c|c|c|c|c|}
\hline & $\begin{array}{c}\text { Valu } \\
\text { e }\end{array}$ & $\begin{array}{l}d \\
f\end{array}$ & $\begin{array}{l}\text { Asymo. } \\
\text { sig ( } 2- \\
\text { sided) }\end{array}$ & $\begin{array}{c}\text { Exa } \\
\text { ct } \\
\text { Sig } \\
\text { (2- } \\
\text { side } \\
\text { d) }\end{array}$ & $\begin{array}{c}\text { Exa } \\
\mathrm{ct} \\
\text { Sig ( } \\
1- \\
\text { side } \\
\text { d) }\end{array}$ \\
\hline Pearson & 1.22 & 1 & .269 & & \\
\hline $\begin{array}{l}\text { Conti.correc } \\
\text { tion }\end{array}$ & .306 & 1 & .580 & & \\
\hline $\begin{array}{l}\text { Likehold } \\
\text { Ratio }\end{array}$ & $\begin{array}{c}1.26 \\
9\end{array}$ & 1 & .260 & & \\
\hline $\begin{array}{c}\text { Fisher Exact } \\
\text { test }\end{array}$ & & & & .586 & .293 \\
\hline $\begin{array}{l}\text { Linear-by- } \\
\text { Linear }\end{array}$ & $\begin{array}{c}1.16 \\
7\end{array}$ & 1 & .280 & & \\
\hline $\begin{array}{l}\text { Association } \\
\mathrm{N} \text { of Valid } \\
\text { Casses }\end{array}$ & 22 & & & & \\
\hline
\end{tabular}

Berdasarkan data penelitian diatas tabel 6 menunjukkan bahwa melalui analisis

chi-square menunjukkan nilai dari asym.Sig (2Sided) menunjukkan nilai 0,269>0,05 dinyatakan bahwa antara teknik jahitan dan kejadian infeksi memiliki hubungan.

Tabel 7. Tabulasi Silang Teknik Jahitan Terhadap Infeksi Luka Perineum Ibu Nifas Di BPM Sri Utami

\begin{tabular}{|c|c|c|c|c|}
\hline & \multicolumn{3}{|c|}{ Kejadian } & \multirow[b]{2}{*}{ Total } \\
\hline & & Infeksi & $\begin{array}{c}\text { Tidak } \\
\text { Infeksi }\end{array}$ & \\
\hline \multirow{2}{*}{$\begin{array}{c}\text { Jahitan } \\
\text { jelujur }\end{array}$} & $\mathrm{N}$ & 3 & 8 & 11 \\
\hline & $\%$ & 27,3 & 72,7 & 100 \\
\hline \multirow{2}{*}{$\begin{array}{l}\text { Jahitan } \\
\text { Terputus }\end{array}$} & $\mathrm{N}$ & 1 & 10 & 11 \\
\hline & $\%$ & 9,1 & 90,9 & 100 \\
\hline \multirow{2}{*}{ Total } & $\mathrm{N}$ & 4 & 18 & 22 \\
\hline & $\%$ & 18,2 & 81,8 & 100 \\
\hline
\end{tabular}

Bahwa sebanyak 3 responden $(27,3 \%)$ mengalami infeksi dengan jahitan jelujur. Sedangkan 10 responden $(90,9 \%)$ tidak mengalami infeksi dengan jahitan terputus.

\section{Pembahasan}

Mengidentifikasi teknik jahitan pada ibu nifas di BPM Sri Utami Surabaya.

Pada data tabulasi silang didapatkan dari 22 responden yang dilakukan jahitan jelujur yang mengalami infeksi sebanyak 3 responden (27,3\%). Teknik jahitan yang biasanya digunakan dalam melakukan penjahitan pada perineum 
Hubungan Teknik Jahitan terhadap Gejala Infeksi Luka Perineum pada Ibu Nifas Hari Keenam di BPM Sri Utami Surabaya

adalah jahitan terputus dan jelujur. Penjahitan yang dilakukan dengan teknik aseptik yang dilanjutkan dengan penyuntikan lidocain untuk memberikan analgesia lokal. Perbaikan perineum tidak boleh dilakukan sampai analgesia efektif. Teknik jahitan terputus digunakan untuk perbaikan otot perineum dalam satu atau dua lapisan bila robekan yang terjadi dalam. Sedangkan jahitan jelujur kelebihanya dapat menutup luka lebih rapat. Namun baik jahitan jelujur maupun terputus tujuannya adalah menutup luka dan menghentikan perdarahan (NHS, 2018).

\section{Mengidentifikasi gejala infeksi luka} perineum pada ibu nifas hari keenam di BPM Sri Utami Surabaya.

Pada data tabulasi silang didapatkan dari 22 responden yang dilakukan jahitan terputus yang tidak mengalami infeksi sebanyak 10 responden $(90,9 \%)$.

Teknik atau cara melakukna penjahitan pada ibu dengan luka perenium ada dua yaitu jahitan satu demi satu/terputus dan jahitan jelujur. Jahitan terputus paling dikenal dan lebih banyak digunakan dengan jarak antara jahitan sebanyak 5-7 mm. Sedangkan jahitan jelujur memberikan pengaruh yaitu mudah dipelajari, rendah rasa nyeri sedikit jahitan, dan lebih cepat. Kelemahanya bila satu jahitan lepas maka akan diikuti oleh jahitan yang lain (Sarwono, 2011). Penelitian yang dilakukan oleh Baiq (2017) menyatakan bahwa tingkat kesembuhan pada ibu postpartum terjadi pada hari keenam. Pada hari tersebut mulai berkurang rasa nyeri dan terbentuk sel - sel kulit baru. Benang pada jahitan mulai terurai, karena luka perenium telah menyatu. Sehingga kejadian infeksi pada hari keenam kemungkinan tidak akan terjadi bila proses penyembuhan luka terjadi dengan baik.

Menganalisis hubungan teknik jahitan terhadap gejala infeksi luka perineum pada ibu nifas hari keenam di BPM Sri Utami Surabaya.

Hasil dari uji chi-square menunjukkan nilai $0,269>0,05$ sehingga terdapat hubungan antara teknik jahitan dengan kejadian infeksi. Baik jahitan jelujur maupun terputus keduanya memiliki fungsi yang sama dalam menutup luka perineum. Kedua teknik jahitan ini memiliki tujuan untuk mempercepat proses menutupnya luka dan mencegah munculnya kejadian infeksi pada ibu nifas hari keenam. Penelitian sebelumnya yang 
Hubungan Teknik Jahitan terhadap Gejala Infeksi Luka Perineum pada Ibu Nifas Hari Keenam di BPM Sri Utami Surabaya

dilakukan oleh Shiriin Hasanpoor (2012) mengenai efek dari jahitan terputus dan jelujur menyatakan luka perineum yang dilakukan penjahitan dengan teknik metode secara terus menerus mampu menstimulasi saraf pada kulit sehingga kejadian infeksi menjadi lebih kecil. Teknik jahitan yang tepat akan membantu dalam menurunkan adanya kejadian infeksi pada ibu postpartum.

\section{Simpulan}

Teknik jahitan penjahitan pada perineum dilakukan secara jelujur (mengalami infeksi sebanyak 27,3\%) dan terputus (tidak mengalami infeksi sebanyak 90, $9 \%$ ). Kedua teknik ini sering kali dilakukan oleh seorang bidan. Hasil dari uji chi-square menunjukkan nilai $0,269>0,05$ sehingga terdapat hubungan antara teknik jahitan dengan kejadian infeksi.

\section{Daftar Pustaka}

Ambarwati, Wulandari. (2010). Asuhan Kebidanan Nifas Yogyakarta : Nuha Medika.

APN. (2017). Buku Acuan Persalinan Normal. Jakarta : JNPK-KR

Aslam, R., Khan, S.A., Amir, Z.u., \& Amir, F., (2015). interrupted versus continuous sutures for repair of episiotomy or 2nd degree perineal tears. Original article J Ayub Medi Coll
Abbottabad. 27(3).

Baiq. (2017). Perbedaan Waktu Penyembuhan Luka Perineum Pada Ibu Postpartum Antara Perawatan dengan $\mathrm{NaCl} 0,9 \%$ Dan Air DTT Di Puskesmas Jetis Yogyakarta. Diakses tanggal 01 maret

2020. www.digilib.unisayogya.ac.id

Bappenas. (2017). Angka kematian ibu.

https://databoks.katadata.co.id/d atapublish/ 2019/05/2020.

Endang L. (2017). Kematian Maternal dan Neonatal dii Indonesia. Fakultas Kesehatan Masyarakat Ul. Diakses tanggal 02 Februari 2020. www.kemkes.go.id > infoterkini > rakerkesnas-2019

Hasanpoor, S., Bani, S., Shahgole, R., \& Gojazadeh, M. (2012). The Effects of Continuous and Interrupted Episiotomy Repair on Pain Severity and Rate of Perineal Repair: A Controlled Randomized Clinical Trial. Journal of Caring Science. https://www.ncbi.nlm.nih.gov/pm c/articles/PMC4161073

Herawati, P. (2010). Hubungan Perawatan Perineum Dengan Kesembuhan Luka Perineum Pada Ibu Nifas Hari Keenam Di Bidan Praktek Swasta (BPS) Ny. Sri Suhersi Mojokerto Kedawung Sragen. Diakses pada tanggal 19 Mei 2019 pukul 10.12 WIB http://unssula.ac.idjurnal.

Dudley, Lynn M., Kettle, C., \& Ismail, Khaled MK. (2013). Secondary suturing compared to nonsuturing for broken down perineal wounds following childbirth Cochrane Systematic Review.

https://www.cochranelibrary.com 
Hubungan Teknik Jahitan terhadap Gejala Infeksi Luka Perineum pada Ibu Nifas Hari Keenam di BPM Sri Utami Surabaya

/cdsr/doi/10.1002/14651858.CD 008977.pub2/full.

Nursalam. (2013). Konsep

Penerapan Metode Penelitian

IImu Keperawatan. Jakarta : Salemba Medika

NHS ( 2018 ) Perineal repair after childbirth. Diakses tanggal 12 februari 2020.

www.nhshealthquality.org

Sarwono P. (2011). Buku Acuan Nasional Pelayanan Kesehatan Maternal Dan Neonatal. Jakarta : YBP.SP

Sriani et.al. (2015). hubungan vulva hygiene dengan pencegahan infeksi luka perineum pada ibu post partum di rumah sakit pancaran kasih gmim manado. Diakses 19 mei2019. https://www.neliti.com/id/

publications /108128. Jurnal Unsrat 